\title{
Estrogen Measurement
}

National Cancer Institute

\section{Source}

National Cancer Institute. Estrogen Measurement. NCI Thesaurus. Code C147335.

The determination of the amount of estrogen present in a sample. 